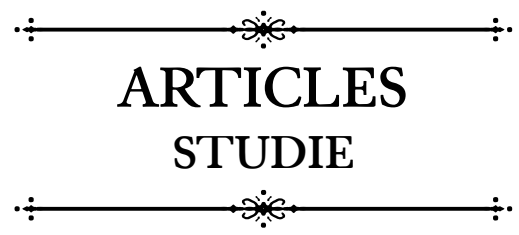

\title{
Aristotelianism in the Philosophy of Mathematics James Franklin
}

The philosophy of mathematics since Frege has been dominated by an oscillation between Platonism and nominalism.

Frege and many later authors defended a Platonist view of the reality of the "abstract objects" of mathematics such as numbers and sets, ${ }^{1}$ while nominalists tried to show that mathematics as applied in science can do without reference to such objects. ${ }^{2}$

To pose the problem in those terms neglects the Aristotelian option: that mathematics may be about some real properties of the (physical and/or nonphysical) world, such as its quantitative properties, or its symmetry, continuity, structure or pattern. Such a view is neither Platonist (since those properties are not in an "abstract" world but realised or at least realisable in the actual world, and in simple cases are perceivable) nor nominalist (since those properties are real aspects of things). Despite some Aristotelian currents in certain authors, there is no recognised complete Aristotelian option or school in the philosophy of mathematics. ${ }^{3}$

\footnotetext{
${ }^{1}$ Notable recent examples include S. Shapiro, Pbilosophy of Mathematics: Structure and Ontology (New York: Oxford University Press, 1997); J. R. Brown, Philosophy of Mathematics: An introduction to the world of proofs and pictures (London: Routledge, 1999); M. Colyvan, The Indispensability of Mathematics (Oxford: Oxford University Press, 2001).

${ }^{2}$ H. Field, Science Without Numbers: A Defence of Nominalism (Princeton: Princeton University Press, 1980); J. Azzouni, Deflating Existential Consequence: a case for nominalism (Oxford: Oxford University Press, 2004).

${ }^{3}$ A preliminary effort in J. Franklin, "Aristotelian realism", in The Philosophy of Mathematics, ed. A. Irvine (Handbook of the Philosophy of Science series, Amsterdam: North-Holland/Elsevier, 2009), 101-153. Other works with Aristotelian tendencies include J. Bigelow, The Reality of Numbers:
} 


\section{James Franklin \\ Aristotelianism in the Philosophy of Mathematics}

An Aristotelian philosophy of mathematics, if it can be sustained, promises to remedy several notable defects in the philosophy of mathematics. First, there is the neglect of applied mathematics, ${ }^{4}$ since both Platonism and nominalism make it hard to see how mathematics can be so successful in real-world applications. Second, there is the conflict between ontology and epistemology in mathematics, with Platonism taking the well-known objectivity of mathematics seriously but leaving it mysterious how we can access objects in another world, and nominalism making epistemology easy but making the objectivity and applicability of mathematics a mystery. ${ }^{5}$ The neglect of epistemology accounts for two strange absences in the philosophy of mathematics: understanding (and mathematics is where one first goes to experience pure understanding) and measurement (the primary way in which mathematics joins to the world). Thirdly, there is the divorce between the philosophy of mathematics, on the one hand, and developmental psychology and mathematics education, on the other - surely the considerable knowledge of infants' mathematical learning ${ }^{6}$ should be compatible with the correct philosophy of mathematics?

An Aristotelian realism shows obvious promise of resolving these tensions, by exhibiting real properties of things that can be the objects of learning in children, the objects of understanding in adults, and the basis of the applications of applied mathematics.

The first task of an Aristotelian philosophy of mathematics is to achieve clarity as to what properties of the real world, exactly, are the objects of mathematics.

A Physicalist's Philosophy of Mathematics (Oxford: Clarendon, 1988); J. Bigelow and R. Pargetter, Science and Necessity (Cambridge: Cambridge University Press, 1990), ch. 2; P. Forrest and D. M. Armstrong, "The nature of number", Philosophical Papers 16 (1987): 165-186; A. D. Irvine, ed., Physicalism in Mathematics (Dordrecht: Kluwer, 1990); P. Maddy, Realism in Mathematics (Oxford: Clarendon, 1990); T. Wilholt, Zabl und Wirklichkeit: Eine philosophische Untersuchung über die Anwendbarkeit der Mathematik (Paderborn: Mentis, 2004).

${ }^{4}$ Noted in S. Körner, The Philosophy of Mathematics: An introductory essay (London: Hutchinson, 1960) and M. Steiner, The Applicability of Mathematics as a Pbilosopbical Problem (Cambridge, Mass: Harvard University Press, 1998).

${ }^{5}$ Noted in P. Benacerraf, "Mathematical truth", Journal of Philosophy 70 (1973): 661-679; nominalist answers include G. Hellman, Mathematics Without Numbers (Oxford: Clarendon, 1989) and M. Leng, Mathematics and Reality (Oxford: Oxford University Press, 2010); Platonist answers include R. C. Koons, Realism Regained (New York, Oxford University Press, 2000), ch. 15.

${ }^{6}$ S. Dehaene, The Number Sense: How the mind creates mathematics (New York: Oxford University Press, 1997); Z. P. Dienes, Building Up Mathematics (London: Hutchinson, 1960), esp. ch. 2; A. Baroody, M.-L. Lai and K. S. Mix, “The development of young children's early number and operation sense and its implications for early childhood education", in Handbook of Research on the Education of Young Children, ed. B. Spodek and O. N. Saracho, $2^{\text {nd }}$ ed. (Mahwah NJ: Lawrence Erlbaum, 2006), ch. 11; comment in P. Kitcher, The Nature of Mathematical Knowledge (New York: Oxford University Press, 1983), 107-8. 


\section{James Franklin \\ Aristotelianism in the Philosophy of Mathematics}

There is an old answer to this question, namely "quantity", which remains partly true but requires some supplementation.

\section{“THE SCIENCE OF QUANTITY"}

From the time of Aristotle to the eighteenth century, one philosophy of mathematics dominated the field. Mathematics, it was said, is the "science of quantity". Quantity is of two kinds, discrete and continuous, studied respectively by arithmetic and geometry.

Aristotle not only provided the general metaphysical framework of nonPlatonist realism but laid down a number of themes specific to mathematics. Mathematics was for him a study of properties of physical things, abstracted from them only in thought:

Obviously physical bodies contain surfaces, volumes, lines and points, and these are the subject-matter of mathematics ... the mathematician does not consider the attributes indicated as the attributes of physical bodies. That is why he separates them, for in thought they are separable from motion ... While geometry investigates physical lengths, but not as physical, [the more physical branch of mathematics,] optics, investigates mathematical lengths, but as physical. ${ }^{7}$

The contrast of this realism with Platonism is explicit: "mathematical objects exist and are as they are said to be", but they are not separate objects. "There are attributes peculiar to animals as being male or as being female (yet there is no male or female separate from animals). So there are properties holding true of things merely as lengths or as planes."

Aristotle also laid out the basic distinction between discrete and continuous quantity, along with the resemblance between them in their both referring to divisibility into parts:

"Quantum" means that which is divisible into two or more constituent parts of which each is by nature a "one" and a "this". A quantum is a plurality if it is numerable, a magnitude if it is measurable. "Plurality" means that which

\footnotetext{
${ }^{7}$ Aristotle, Physics II, 2, 193 b 23-194a11, discussed in J. Lear, "Aristotle's philosophy of mathematics", Philosopbical Review 91 (1982): 161-192; H. Mendell, "Aristotle and mathematics", in Stanford Encyclopedia of Philosophy (Summer 2004 edition), Edward N. Zalta (ed.), URL = 〈http://plato.stanford.edu/archives/ sum2004/entries/aristotle-mathematics/ $>$.

${ }^{8}$ Aristotle, Metaphysics XIII, 3, 1077 b 18-1078 a 9.
} 


\section{James Franklin \\ Aristotelianism in the Philosophy of Mathematics}

is divisible potentially into non-continuous parts, "magnitude" that which is divisible into continuous parts. ${ }^{9}$

And on discrete quantity, he emphasized - if a little cryptically - the relativity of number to the universal being used to divide the mass being counted into units:

"The one" means the measure of some plurality, and "number" means a measured plurality and a plurality of measures ... The measure must always be some identical thing predicable of all the things it measures, e.g. if the things are horses, the measure is "horse", and if they are men, "man". If they are a man, a horse, and a god, the measure is perhaps "living being", and the number of them will be a number of living beings. ${ }^{10}$

Likewise in continuous quantity, he noted the reliance of measurement on relation to the quantity we take for a unit: “... measure means that by which each thing is primarily known, and the measure of each thing is a unit-in length, breadth, depth, weight and speed ... In all these cases, then, the measure and starting-point is some indivisible unit (since even in the case of lines we treat the one-foot line as indivisible)." 11 That is not to say that Aristotle takes quantity itself to be relative; simply that our knowledge or measurement of it must be relative to a unit.

By the seventeenth and eighteenth centuries, a version of an Aristotelian theory of mathematics as a realist science of quantity, both discrete and continuous, was standard. ${ }^{12}$ Newton writes of continuous quantity, in his characteristic magisterial style:

By Number we understand not so much a Multitude of Unities, as the abstracted Ratio of any Quantity, to another Quantity of the same kind, which we take for Unity. ${ }^{13}$

${ }^{9}$ Aristotle, Metaphysics V, 13, 1020a7-12.

${ }^{10}$ Aristotle, Metaphysics XIV, 1, 1088a 4-11; further in H. G. Apostle, Aristotle's Philosophy of Mathematics (Chicago: Chicago University Press, 1952); V. E. Smith, St Thomas on the Object of Geometry (Milwaukee: Marquette University Press, 1954); D. Bostock, "Aristotle's philosophy of mathematics", in Oxford Handbook on Aristotle, to appear.

${ }^{11}$ Aristotle, Metaphysics X, 1, 1052 b 22-30.

${ }^{12}$ E.g. I. Barrow, The Usefulness of Mathematical Learning Explained and Demonstrated (London, 1734, repr. London: Cass, 1970), 10-15; Encyclopaedia Britannica, $1^{\text {st }}$ ed. (Edinburgh, 1771), article "Mathematics", vol. III, 30-31; P. Mancosu, Philosophy of Mathematics and Mathematical Practice in the Seventeenth Century (New York: Oxford University Press, 1996), 16, 35-37, 56, 88; D. M. Jesseph, Berkeley's Philosophy of Mathematics (Chicago: University of Chicago Press, 1993), ch. 1.

${ }^{13}$ I. Newton, Arithmetica Univeralis (1728), 2; similar in L. Euler, Elements of Algebra, $3^{\text {rd }}$ ed. (London, 1822); both discussed in Bigelow and Pargetter, Science and Necessity, 60-61. 


\section{James Franklin \\ Aristotelianism in the Philosophy of Mathematics}

The realist quantity theory apparently then died of inanition. A version of it was defended by John Stuart Mill, but the criticisms of Mill made by Frege were generally thought to have ruled out any such realist theory.

The quantity theory plainly gives an initially reasonable picture of at least elementary mathematics, with its emphasis on counting, measuring, and calculating with the resulting numbers. It promises direct answers to questions about what the object of mathematics is (certain properties of physical and possibly non-physical things such as their size), and how those properties are known (the same way other natural properties of physical things are known - by perception in simple cases and inference from perception in more complex ones). Let us examine quantity more closely from a modern point of view.

\section{QUANTITY: CONTINUOUS QUANTITY AND RATIOS}

The division of quantity into continuous and discrete at least highlights the fact that it is far from clear initially whether the two kinds have much in common, for example whether the ratio "the double" has much in common with the counting number 2 . So let us examine them separately.

The crucial concept of continuous quantity is that of ratio or proportion. John Bigelow, one of the most Aristotelian of recent philosophers of mathematics, introduces ratios as follows. The Aristotelian language is chosen to keep close to physically real relations, and also to remind us how easily we deal with the reality of relations, and relations between relations:

Physical objects, like elephants and Italians, humming-birds and Hottentots, have many physical properties and relations: volume and surface area, for example. And the physical properties of these objects stand in important relations to one another. In particular, such physical properties stand in relations of proportion to one another. There is a relation between the surface area of the humming-bird and that of the Hottentot; and this may or may not be the same as the relationship that holds between the surface areas of an Italian and an elephant.

Relationships such as proportion will hold not only between surface areas but also between volumes. Conceivably, the relationship between the surface areas of two objects might be the same as the relationship between volumes for two other objects. But it is a fact of considerable biological significance that the relation between surface areas of two objects will not, in general, be the same as the relationship between their volumes. Ignoring differences in shape (say, by supposing an elephant were shaped like an Italian, or vice versa), it turns out that if the elephant has ten times the height then it will have a hundred times the surface area and a thousand times the volume. The 


\section{James Franklin \\ Aristotelianism in the Philosophy of Mathematics}

volumes of the elephant and the Italian, or the Hottentot and the hummingbird, will be "more different" than their surface areas. There are several distinct relationships present; furthermore, there are distinctive ways in which these relationships differ from one another. There are also distinctive relationships among these relationships. These facts have consequences of physical significance: for instance, with regard to problems of heat regulation. It is from such fertile soil as this that most of mathematics has grown. ${ }^{14}$

Thus for example the universal "being 1.57 kilograms in mass" stands in a certain relation, a ratio, to the universal "being 0.35 kilograms in mass". Pairs of lengths can stand in that same ratio, as can pairs of time intervals. The ratio itself is just what those binary relations between pairs of masses, lengths and time intervals have in common ("A ratio is a sort of relation in respect of size between two magnitudes of the same kind": Euclid, book V, definition 3). Thus there are determinate relations such as "being one-third the volume of" that hold between physical objects, and then there are "topic-neutral" ratios which are relations between those determinate relations - for example, the ratio $3: 2$ holds between "being three times as massive as" and "being twice as massive as". ${ }^{15}$

The theory of the ancients that the science of continuous quantity is geometry does need some qualification. It was always hard to regard shape as straightforwardly "quantity" - it contrasts with size, rather than resembling it - though geometry certainly studies it. Further, there is an alternative body of knowledge with a better claim to being the science of continuous quantity in general, namely, the calculus. Stemming from Aristotelian debates on the continuum, ${ }^{16}$ the study of continuity requires the notion of a limit, as described and made use of in the differential calculus of Newton and Leibniz, and made more rigorous in the real analysis of Cauchy and Weierstrass.

\section{MEASUREMENT AND THE APPLICABILITY OF MATHEMATICS}

As a case study on what such an Aristotelian perspective on (continuous) quantity can do, we present recent realist work on measurement theory.

${ }^{14} \mathrm{~J}$. Bigelow, "Sets are haecceities", in Ontology, Causality and Mind: Essays in Honour of D. M. Armstrong, ed. J. Bacon, K. Campbell and L. Reinhardt (Cambridge: Cambridge University Press, 1993) ch. 4 , at $74-75$.

${ }^{15}$ D. M. Armstrong, "Are quantities relations? A reply to Bigelow and Pargetter", Pbilosopbical Studies 54 (1988): $305-316$.

${ }^{16}$ A. Newstead, "Aristotle and Modern Mathematical Theories of the Continuum", in Aristotle and Contemporary Science II, ed. D. Sfendoni-Mentzou, J. R. Brown and J. Hattiangadi (Frankfurt am Main: Peter Lang, 2001), 113-129. 


\section{James Franklin \\ Aristotelianism in the Philosophy of Mathematics}

Nowhere is the divergence between the Aristotelian and Platonist standpoints more obvious than in how they approach the problem of the applicability of mathematics. That very description of the problem has a Platonist bias, as if the problem is about the relations between "abstract" mathematical entities and something distinct from them in the "world" to which they are "applied". On an Aristotelian view, there is no such initial separation between mathematics and its "applications", since the quantity, symmetry, continuity and so on that pure mathematics studies is the same symmetry and continuity that is found in the physical world.

That undesirable assumed split between mathematical entities and their "applications" is first evident in accounts of measurement. Considering the fundamental importance of measurement as the first point of contact between mathematics and what it is about, it is surprising how little attention has been paid to it in the standard literature of the philosophy of mathematics. What work there has been has tended to concentrate on "representation theorems" that describe the conditions under which quantities can be represented by numbers. ${ }^{17}$ "Measurement theory officially takes homomorphisms of empirical domains into (intended) models of mathematical systems as its subject matter", as one recent writer expresses it. ${ }^{18}$ That again poses the problem as if it is one about the association of numbers to parts of the world, which inevitably leads to a Platonist perspective on the problem.

But a closer look suggests an Aristotelian reinterpretation. What is it about the quantitative properties of the measured world that ensures that a homomorphism to numbers exists? The standard treatment (of measurement of length) begins by looking at the properties of concatenating identical rods, and axiomatising those properties as a basis for showing that the homomorphism exists. ${ }^{19}$ But the quantitative properties exist prior to the homomorphism and are the condition of its existence: as the Aristotelian maintains, the system of ratios of lengths, for example, pre-exists in the physical things being measured, and measurement consists in identifying the ratios that are of interest in a particular case; the arbitrary choice of unit that allows ratios to be converted to digital

${ }^{17}$ E.g. C. W. Savage and P. Ehrlich, Philosophical and Foundational Issues in Measurement Theory (Hillsdale, NJ: L. Erlbaum, 1992).

${ }^{18}$ Azzouni, Deflating Existential Consequence, 161.

${ }^{19}$ D. H. Krantz, R. D. Luce, P. Suppes and A. Tversky, Foundations of Measurement, vol. I (New York: Academic, 1971), ch. 1. 


\section{James Franklin \\ Aristotelianism in the Philosophy of Mathematics}

numerals for ease of calculation is something that happens at the last step. ${ }^{20}$ That in turn suggests an Aristotelian realist view of the real numbers arising in measurement. As the Australian Aristotelian Michell puts it, in language similar to that used of ratios above:

The commitment that measurable attributes sustain ratios has a further implication, viz., that the real numbers are spatiotemporally located relations. It commits us to a realist view of number. If Smith's weight is $90 \mathrm{~kg}$, then this is equivalent to asserting that the real number, 90 , is a kind of relation, viz., the kind of relation holding between Smith's weight and the weight of the standard kilogram. Since these weights are real, spatiotemporally located instances of the attribute, any relation holding between them will likewise be real and spatiotemporally located. This kind of relation is what was referred to above as a ratio. So the realist view of measurement implies that real numbers are ratios. By way of contrast, the standard view within the philosophy of mathematics is that numbers are abstract entities of some kind, entities not intrinsic to the empirical context of measurement, but related externally to features of that situation by human convention. This neatly fits the representational view of measurement and in the zoth century, the representational view has dominated philosophical thinking about measurement. The representational view was strongly informed by non-realist thinking within the philosophy of mathematics. ${ }^{21}$

\section{QUANTITY: DISCRETE QUANTITY, NUMBERS AND SETS}

Discrete quantities arise in quite a different way from ratios. It is characteristic of "unit-making" or "count" universals like "being an apple" or "being a horse" (in Aristotle's example) to structure their instances discretely. That is what distinguishes them from mass universals like "being water". A heap of apples stands in a certain relation to "being an apple". That relation is the number of apples in the heap. The same relation can hold between a heap of shoes and "being a shoe". The number is just what these binary relations have in common. ${ }^{22}$

Thus, suppose there are seven black swans on the lake now. The proposition refers to a part of the world, the black biomass on the lake, and a structuring

${ }^{20}$ Similar comments in Bigelow and Pargetter, Science and Necessity, 60-61.

${ }^{21}$ J. Michell, "The logic of measurement: a realist overview", Measurement 38 (2005): 285-294; relation to Aristotle discussed in C. B. Crowley, Aristotelian-Thomistic Philosophy of Measure and the International System of Units (SI) (Lanham, Md: University Press of America, 1996).

${ }^{22}$ From D. M. Armstrong, Sketch for a Systematic Metaphysics (Oxford: Oxford University Press, 2010), ch. 13; originally from P. Forrest and D. M. Armstrong, "The nature of number", Pbilosophical Papers 16 (1987): 165-186; and mostly in G. Kessler, "Frege, Mill and the foundations of arithmetic", Journal of Philosophy 77 (1980): 65-79. 


\section{James Franklin \\ Aristotelianism in the Philosophy of Mathematics}

property, being a black swan on the lake now. Both are necessary to determining that the relation between the mass and the property should be "seven": if it were a different mass (e.g. the black swans on or beside the lake) or a different unitmaking property (e.g. being a swan organ on the lake now) then the numerical relation would be different. Therefore numbers are not properties of parts of the world simply, but must be properties of the relation between parts of the world and the unit-making properties that structure them.

So the fact that the heap of shoes stands in one such numerical relation to "being a shoe" and another numerical relation to "being a pair of shoes" (made much of by Frege $^{23}$ ) does not show that the number of a heap is subjective, or not about something in the world, but only that number is relative to the count universal being considered. For Aristotelians, the universal is real and so is its relation to the heap it structures.

Whereas ratios have nothing to do with sets, numbers are intimately connected with them. Given a set, there is something to count. And conversely, if there is counting, there is a set of entities being counted, and indeed sets are good for little else. Given a heap and a unit-making property structuring it, there is immediately created (there supervenes) both the set of things of which the heap is the mereological sum, and a number of things in that set. If there is no unitmaking property - if there is just stuff - there is no number and no set. If there is a unit-making property, there is a set and a number of elements in the set.

So what are sets, from an Aristotelian point of view? The Aristotelian cannot rest content with the Platonist story that sets are a simple Platonist entity at which questions should stop, and that the membership relation is sui generis. That conception is problematic, but even if it were intelligible and satisfactory, it would interpose a Platonist entity in a story where there should be no role for it, the story of how unit-making properties structure a heap into something able to be counted.

The Aristotelian desires a theory according to which sets are ontologically nothing over and above there being a unit-making property to structure a heap. Several closely-related theories are available. The leading one is that of David Armstrong. He adopts David Lewis's proposal that a set is the mereological sum of its singletons, and adds the idea that the singleton of $x$ is simply the

${ }^{23}$ G. Frege, The Foundations of Arithmetic (1884), trans. J. L. Austin, $2^{\text {nd }}$ revised ed. (Oxford: Blackwell, 1980), §22, p. 28 and $\S 54$, p. 66. 
state of affairs of there being some unit-making universal that singles out $x .^{24}$ The essence of the suggestion is that at the basic philosophical level necessary in these questions, we cannot help ourselves naively to the notion of "object". When we assert "The cat sat on the mat", "The", in "the cat", indicates that we are dealing with a single unified object, cut out from the background. In the apparent continuum of matter that is the universe and the flux it undergoes, what cuts out the single warm furry item, draws its boundaries and points it out as an individual thing deserving a common noun ${ }^{25}$ It is the property, the repeatable unit-making property "being a cat", that cuts the cat from the background, and in doing so creates a singleton (and when actually repeated creates other sets) and at the same time creates something to be counted.

This view of sets raises the possibility that small sets of physical objects should be directly perceivable, as argued by Maddy. ${ }^{26}$ If I open an egg carton and see that there are three eggs in it, I perceive both the pale curved surface of the egg-heap and that it is structured by "being an egg" into three parts, each an egg. That is sufficient to perceive the heap as a set of three eggs.

Perception of sets of sets of physical objects is not beyond our capabilities either. For example, in this diagram,

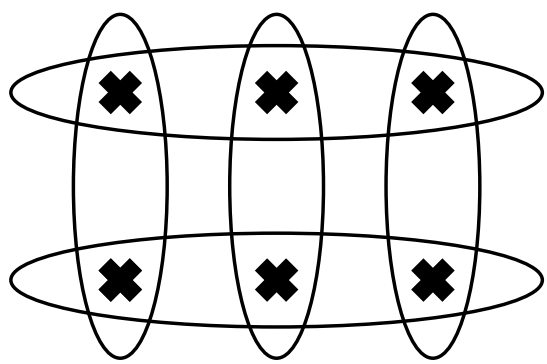

Fig. 1

Why $2 \times 3=3 \times 2$

the point of the ovals is to guide the visual system so as to see the six objects as alternately two sets of triples and three sets of pairs. That is what allows the intellect to grasp the relation between the parts and hence achieve its certain

${ }^{24}$ D. M. Armstrong, "Classes are states of affairs", Mind 100 (1991): 189-200; several proposals listed in A. Paseau, "Motivating reductionism about sets", Australasian Journal of Philosophy 86 (2008): 295-307.

${ }^{25}$ B. C. Smith, On the Origin of Objects (Cambridge, Mass: MIT Press, 1996).

${ }^{26}$ P. Maddy, Realism in Mathematics, 58-67. 
knowledge of the equation $2 \times 3=3 \times 2$, based on its understanding of why it must be so.

\section{“THE SCIENCE OF STRUCTURE”}

It became clear that, even if the "science of quantity" theory were correct about elementary mathematics, it was not adequate to cover some of the subjectmatters of modern higher mathematics. A contemporary Aristotelian philosophy of mathematics must expand its view of the objects of mathematics.

The earliest case of a serious mathematical problem that seemed clearly not well described as being about "quantity" was Euler's example of the bridges of Königsberg. The bridges connected two islands and two riverbanks as shown in the diagram.

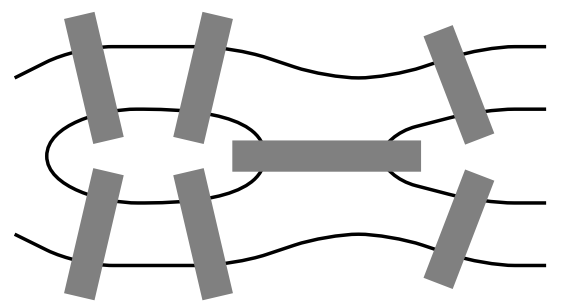

Fig. 2

The bridges of Königsberg

The citizens of Königsberg in the eighteenth century noticed that it was impossible to walk over all the bridges once, without walking over at least one of them twice. Euler proved they were correct. ${ }^{27}$ The result is intuitively about the "arrangement" or pattern of the bridges, rather than about anything quantitative like size or number. As Euler puts it, the result is "concerned only with the determination of position and its properties; it does not involve measurements." The length of the bridges and the size of the islands are irrelevant. That is why we can draw the diagram so schematically. All that matters is which land masses are connected by which bridges. Euler's result is now regarded as the pioneering effort in the topology of networks. There now exist large bodies of work on such topics as graph theory, networks, and operations research problems like timetabling, where the emphasis is on arrangements and connections rather than quantities.

${ }^{27}$ L. Euler, "Solutio problematis ad geometriam situs pertinentis" (1776), trans. in Graph Theory 1736-1936, ed. N. Biggs, E. Lloyd and R. Wilson (Oxford: Clarendon, 1976), 3-8. 


\section{James Franklin \\ Aristotelianism in the Philosophy of Mathematics}

A second kind of example where structure contrasts with quantity is symmetry, brought to the fore by nineteenth-century group theory and twentiethcentury physics. Symmetry is a real property of things, things which may be but need not be physical (an argument, for example, can have symmetry if its second half repeats the steps of the first half in the opposite order; Platonist mathematical entities, if any existed, could be symmetrical). The kinds of symmetry are classified by group theory, the central part of modern abstract algebra. ${ }^{28}$

In the 1990s, there was a prominent "structuralist" school in the philosophy of mathematics, led by Resnik and Shapiro, which rightly highlighted the role of structure in mathematics. ${ }^{29}$ However they viewed structures as a Platonist entity similar to sets.

\section{CONCLUSION}

Platonists and nominalists have comprehensively exposed each others' inadequacies in the philosophy of mathematics. The resources are now available for a revival of Aristotelian realism. It will not be in the strict Aristotelian tradition of the "science of quantity", but will still be a moderate realist view, neither Platonist nor nominalist, which will include quantity in the subject-matter of mathematics.

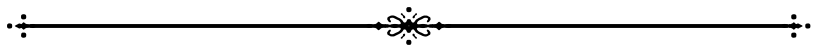

James Franklin is professor of mathematics and statistics at the University of New South Wales. He is the author of The Science of Conjecture: Evidence and Probability Before Pascal; Corrupting the Youth: A History of Philosophy in Australia; What Science Knows: And How It Knows It, and other books. He has completed a book on Aristotelian philosophy of mathematics.

Address: School of Mathematics and Statistics, University of New South Wales, Sydney 2052, Australia

E-mail: j.franklin@unsw.edu.au

Web: http://web.maths.unsw.edu.au/ -jim/

\footnotetext{
${ }^{28}$ H. Weyl, Symmetry (Princeton: Princeton University Press, 1952); G. Hon and B. R. Goldstein, From Summetria to Symmetry: The making of a revolutionary scientific concept (Dordrecht: Springer, 2008).

${ }^{29}$ S. Shapiro, Pbilosophy of Mathematics: Structure and Ontology (New York: Oxford University Press, 1997); M. D. Resnik, Mathematics as a Science of Patterns (Oxford: Oxford University Press, 1997).
} 
James Franklin

Aristotelianism in the Philosophy of Mathematics

\section{SUMMARIUM}

\section{De philosophia mathematicae Aristotelica}

Philosophia mathematicae bodierna aut Platonismum, aut nominalismum amplectitur, realismo Aristotelico neglecto remanente. Secundum sententiam Aristotelicam mathematica circa formas seu rationes, quae vere in rebus reperiuntur, agit. Mathematica ergo non versatur circa "obiecta abstracta" incorporea, ut Platonici volunt, nec est mera "lingua scientiarum", ut nominalistae docent. Sententia Aristotelis, mathematicam scil. esse "scientiam quantitatis", ad minimum arithmeticae elementaris indolem bene exprimit. Ratio nempe seu proportio e. $g$. duarum altitudinum est perceptibilis mensurabilisque relatio realis inter duas formas a parte rei repertas. In eadem proportione quoque duo pondera aut intervalla temporis convenire possunt. Proportio seu ratio est exemplar quantitatis continuae; sed etiam quantitates discretae, ut numeri integri, sunt relationes, videlicet multitudinis ad universale, quod unitatem definit. Numerus e. g. foliorum arboris est relatio frondis ad "folium-esse"; quae relatio aequalis esse potest relationi, quam multitudo caligarum dicit ad "caligam-esse". Sublimior mathematica bodierna autem circa formas quandas reales, quae naturaliter non videntur esse quantitates, versatur; quapropter definitio mathematices ut "scientiae quantitatis" laxari debere videtur. Symmetria, topologia et similia sunt obiectum mathematices, non tamen praecise dicunt quantitatem, sed potius structuram, ordinem, dispositionem partium in toto etc.

\section{ABSTRACT \\ Aristotelianism in the Philosophy of Mathematics}

Modern philosophy of mathematics has been dominated by Platonism and nominalism, to the neglect of the Aristotelian realist option. Aristotelianism bolds that mathematics studies certain real properties of the world - mathematics is neither about a disembodied world of "abstract objects", as Platonism bolds, nor it is merely a language of science, as nominalism bolds. Aristotle's theory that mathematics is the "science of quantity" is a good account of at least elementary mathematics: the ratio of two heights, for example, is a perceivable and measurable real relation between properties of physical things, a relation that can be shared by the ratio of two weights or two time intervals. Ratios are an example of continuous quantity; discrete quantities, such as whole numbers, are also realised as relations between a beap and a unit-making universal. For example, the relation between foliage and being-a-leaf is the number of leaves on a tree, a relation that may equal the relation between a beap of shoes and being-a-shoe. Modern bigher mathematics, however, deals with some real properties that are not naturally seen as quantity, so that the "science of quantity" theory of mathematics needs supplementation. Symmetry, topology and similar structural properties are studied by mathematics, but are about pattern, structure or arrangement rather than quantity. 